\title{
A gridded hourly precipitation dataset for Switzerland using rain-gauge analysis and radar-based disaggregation
}

\author{
Marc Wüest, ${ }^{\mathrm{a} *}$ Christoph Frei, ${ }^{\mathrm{a}, \mathrm{b}}$ Adrian Altenhoff, ${ }^{\mathrm{a}}$ Martin Hagen, ${ }^{\mathrm{c}}$ Michael Litschi ${ }^{\mathrm{a}}$ \\ and Christoph Schär ${ }^{\mathrm{a}}$ \\ a Institute for Atmospheric and Climate Science, ETH Zürich, Switzerland \\ ${ }^{\mathrm{b}}$ Federal Office of Meteorology and Climatology MeteoSwiss, Zürich, Switzerland \\ c Deutsches Zentrum für Luft- und Raumfahrt, Oberpfaffenhofen, Germany
}

\begin{abstract}
Rain gauges and weather radars both constitute important devices for operational precipitation monitoring. Gauges provide accurate yet spotty precipitation estimates, while radars offer high temporal and spatial resolution yet at a limited absolute accuracy. We propose a simple methodology to combine radar and daily rain-gauge data to build up a precipitation dataset with hourly resolution covering a climatological time period. The methodology starts from a daily precipitation analysis, derived from a dense rain-gauge network. A sequence of hourly radar analyses is then used to disaggregate the daily analyses. The disaggregation is applied such as to retain the daily precipitation totals of the raingauge analysis, in order to reduce the impact of quantitative radar biases. Hence, only the radar's advantage in terms of temporal resolution is exploited. In this article the disaggregation method is applied to derive a 15-year gridded precipitation dataset at hourly resolution for Switzerland at a spatial resolution of $2 \mathrm{~km}$. Validation of this dataset indicates that errors in hourly intensity and frequency are lower than $25 \%$ on average over the Swiss Plateau. In Alpine valleys, however, errors are typically larger due to shielding effects of the radar and the corresponding underestimation of precipitation periods by the disaggregation. For the flatland areas of the Swiss Plateau, the new dataset offers an interesting quantitative description of high-frequency precipitation variations suitable for climatological analyses of heavy events, the evaluation of numerical weather forecasting models and the calibration/operation of hydrological runoff models. Copyright (C) 2009 Royal Meteorological Society
\end{abstract}

KEY WORDS radar; rain-gauge; disaggregation; hourly precipitation rate; climatology; precipitation intensity; precipitation frequency; ch02h

Received 3 October 2008; Revised 21 August 2009; Accepted 22 August 2009

\section{Introduction}

Rain-gauge instruments and meteorological radars both constitute important devices of operational precipitation monitoring. Yet the data provided by the two platforms has distinct characteristics and its utility in specific applications critically depends on the relative advantages or disadvantages.

Rain-gauge networks, on one hand, provide a set of point measurements. In Europe, networks typically exhibit an inter-station distance of $10-50 \mathrm{~km}$ (even coarser in remote areas) and a temporal resolution between $10 \mathrm{~min}$ and 1 month (New et al., 1999; Frei and Schär, 1998). Although rain-gauge measurements are affected by a systematic bias (Neff, 1977; Yang et al., 1999), they are comparatively accurate. In Europe, daily and monthly records from rain-gauge networks range back over many decades and this makes them an interesting resource for climate-related analyses (Auer

\footnotetext{
* Correspondence to: Marc Wüest, ETH Zürich, Institute for Atmospheric and Climate Science, Universitätstrasse 16, CH-8093 Zürich, Switzerland. E-mail: marc.wueest@env.ethz.ch
}

et al., 2005; Schmidli and Frei, 2005; Klok and Klein Tank, 2007). Today's networks of automatic stations with hourly and higher time resolution are still coarse and it is therefore not possible to derive an areal picture of the sub-daily precipitation evolution from rain gauges alone.

On the other hand, observations from precipitation radars are spatially and temporally very detailed. Current radar composites in European countries reveal the evolution of precipitation in quasi-real time, at full spatial coverage, with a resolution of a few kilometers and at intervals of a few minutes (Meischner et al., 1997; Hagen, 1999; Koistinen and Michelson, 2002). In Europe, the continuous operation of radar networks started about 20 years ago. However, the absolute accuracy of radar-based precipitation estimates is restricted by several technical limitations such as restricted visibility, ground clutter and limitations in rain-rate conversions (Joss and Waldvogel, 1990; Germann et al., 2005). Moreover retrieval and compositing techniques have frequently changed. Although substantial progress has been made towards higher accuracy, the utility of radar-based rainfall estimates in climatological applications and for long-term 
hydrological modelling is still limited (Guo et al., 2004; Neary et al., 2004).

Several procedures have been proposed to combine rain-gauge and radar-based rainfall estimates in order to exploit the benefits of both monitoring platforms. One category of combination methods encompasses gauge adjustment techniques where radar fields are calibrated to rain-gauge measurements (Barbosa, 1994; Borga et al., 2002). Real-time or climatological adjustments are now adopted in various forms for most operational radar products in Europe. Gjertsen et al. (2004) give an overview of such procedures. Another category of techniques adopts geostatistical concepts, where radar information is exploited in gridding techniques for rain-gauge data (Seo, 1998; Haberlandt, 2007). The distinction between the two categories is somewhat ambiguous. Both procedures are confronted with the difficulty to extrapolate differences between radar and gauge measurements into space, and the solution to this will decide on how much of the radar's fine-scale information will be saved into the final analysis.

The present study proposes a combination of radar and rain-gauge data that does not aim primarily at incorporating fine-scale spatial information from radar. Our combination addresses applications that require precipitation analyses over a climatological time scale (i.e. several years) and at a sub-daily time resolution, but can live with the spatial resolution offered by standard rain-gauge networks. While several gridded precipitation analyses are currently available at the daily time scale and with resolutions of about $20 \mathrm{~km}$ (Frei and Schär, 1998; Rubel and Hantel, 2001; Haylock et al., 2007), there is a lack in similar datasets for the sub-daily time scale. There is considerable interest in such datasets, for example, for climatological analysis of short-term precipitation extremes, for the validation of numerical weather prediction and climate models, and as forcing data for hydrological models.

Our combination of radar and gauge data is comparatively simple. It is based on a daily gridded precipitation analysis, which is derived from rain-gauge data exclusively, but makes full use of all available gauges including the dense network of conventional, notautomated, and daily measurements. The hourly sequence of radar analyses on the other hand is used for disaggregating the daily analyses. The disaggregation retains the daily precipitation totals of the rain-gauge analysis and hence, reduces effects from quantitative radar errors.

In this paper we describe the technical details in the derivation of such an hourly precipitation analysis for Switzerland extending over a continuous 15 -year period (Sections 2 and 3). Moreover, we evaluate the quality of this dataset by comparing the independent hourly rain-gauge measurements, focusing on the representation of climatological characteristics, such as the distribution function of hourly precipitation (Section 4). Furthermore, we present some specific analyses of the dataset, to illustrate its potential applications (Section 5).

\section{Underlying datasets}

\subsection{Rain-gauge observations}

The Federal Institute of Meteorology and Climatology MeteoSwiss maintains a network of approximately 450 rain-gauges covering the country at an inter-station distance of $10-15 \mathrm{~km}$ (Figure 1a). These stations provide daily precipitation totals from automated or manual readings. By convention, the daily totals are valid from 0540 UTC to 0540 UTC of the next calendar day. Additional characteristics of the network are described in Konzelmann et al. (2007) and Frei and Schär (1998). In this study, the high-resolution station data for 1992-2003 provides the basis for a daily precipitation analysis onto a regular mesoscale grid (Section 3.1), which is subsequently subject to radar-based temporal disaggregation.

A subset of 72 rain-gauge stations in Switzerland - the ANETZ network (Figure 1b) - is operated automatically by MeteoSwiss exhibiting a temporal resolution of $10 \mathrm{~min}$. In this study the higher temporal resolution of these stations will be exploited as reference to evaluate the new hourly precipitation dataset. Note that several of the evaluation stations are located in the high-mountain Alpine areas.

\subsection{Weather radar observations}

MeteoSwiss is operating a network of three weather radar stations that essentially sound the territory of Switzerland (Figure 1; Germann et al., 2006). For the purpose of this study we use a composite of rain rate retrievals from the

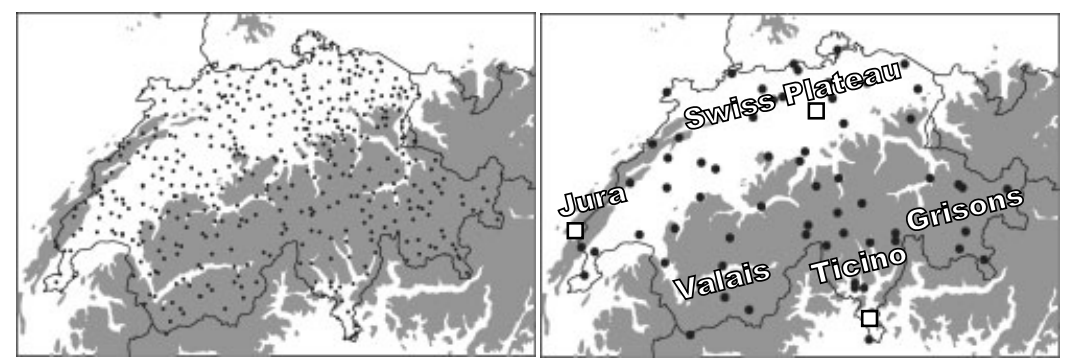

Figure 1. Network of conventional rain gauges offering daily precipitation totals (a) and automatic rain gauges providing rain rates every 10 min (b). In addition, the three Swiss weather radars are indicated with squares. Grey shaded areas represent elevations above $800 \mathrm{~m}$ ASL. Note also the geographic names used in the text. 
three radars at a 5-min time interval starting in January 1992 and ending in December 2003. For the region south of the Alps (Ticino), the composite is only available from October 1994, after the installation of the third radar station on Monte Lema. The radar composite exhibits a horizontal resolution of $2 \times 2 \mathrm{~km}^{2}$ and precipitation rates are given in seven logarithmic classes: $0,0-1$, $1-3,3-10,10-32,32-100,>100 \mathrm{~mm} / \mathrm{h}$. A detailed description of the Swiss radar measurements is given in Germann et al. (2006). Here we summarize those characteristics that are directly relevant for the current study.

The Swiss radars are set up to measure 20 elevations between $-0.3^{\circ}$ and $45^{\circ}$ at a temporal resolution of 5 min. The composite map used for the study represents the maximum value of the 20 elevations over each position on the horizontal grid. The maximum value does not necessarily originate from the lowest elevation, as precipitation particles may break-up and evaporate as they fall. Especially the bright band effect, i.e. melting particles, yields a high scattering cross section to the radar pulse. Hence, in cases when the melting layer is above ground level, the compositing technique has a tendency to overestimate precipitation. We will refer to this error source as:

- factor A (elevation): Errors due to the neglecting of positive (coalescence, aggregation, riming, deposition) or negative (evaporation, break-up) hydrometeor growth beneath the available elevation of the radar beam.

The topography in Switzerland is highly complex. As result the atmosphere in many Alpine valleys is not directly visible from the radars. Although profile corrections have been introduced (Germann and Joss, 2002) limited visibility remains an error source in radar composites. We refer to this as:

- factor B (shadowing): Errors due to orographic shading. In our application this error source manifests primarily in a too short lifetime of precipitation systems that evolve below the radar horizon, as is typically the case for convective systems that tend to develop from low to high altitudes.

Weather radars measure the scattered echo from an ensemble of hydrometeors in a pulse volume. For the Swiss radar system the pulse volume is typically $1 \mathrm{~km}^{3}$ and depends on the antenna characteristics, the distance from and position relative to the radar site. Hence, there is a fundamental difference in the space-time characteristics between radar and rain-gauge measurements, which we will refer to as:

- factor C (pulse volume): Limited comparability between radar and rain-gauge measurements due to the differing spatial sampling. This effect yields a smoothing of radar compared to rain-gauge time series, especially in convective cells with hail curtains smaller than the pulse volume.

The mentioned factors and additional complications in radar-based estimates (e.g. attenuation, missing knowledge of hydrometeor type and shape) limit the absolute accuracy of radar-based precipitation estimates. While our use of radar data (Section 3) tries to minimize the negative impact of these factors, they may nevertheless affect the quality of the final hourly dataset. These effects will be investigated and discussed in Section 4.

\section{Methods}

The derivation of the hourly gridded precipitation dataset for Switzerland has three steps, starting with the construction of a daily gridded rain-gauge analysis, the preprocessing of radar composites and finally the disaggregation of daily analysis using the radar sequence. Details of these three steps are described in the following subsections.

\subsection{Rain-gauge analysis}

The construction of the daily gridded precipitation analysis for Switzerland follows essentially the same procedure like that described in Frei et al. (2006; Section 4.1). The only difference is the target resolution of about $2 \mathrm{~km}$. In summary, the daily rain-gauge observations are first converted into relative anomalies from the long-term mean of the corresponding calendar month. These relative anomalies are then interpolated onto a regular grid using the angular distance weighting scheme Synteny Mapping and Analysis Program (SYMAP) by Shepard (1968, 1984; see also Frei and Schär, 1998). SYMAP accounts for the directional isolation of rain-gauge stations around the target grid point and adopts a variable search radius depending on local station density. Interpolated anomalies are then scaled back using the high-resolution precipitation climatology of Schwarb et al. (2001). The climatology was derived with the local regression approach PRISM, specifically calibrated for the Alpine region (Daly et al., 1994, 2002; Schwarb, 2000).

Conducting the spatial analysis in terms of relative anomalies as opposed to real precipitation values has the advantage of taking a more accurate account of systematic topographic effects on precipitation variability. An antecedent analysis of long-term mean values with more sophisticated procedures using topographic features as predictors avoids adverse effects of the limited representativeness of the station network on the analysis (Widmann and Bretherton, 2000 for more detail.)

The gridded daily anomalies (with respect to their local monthly mean precipitation) were then scaled with the highly resolved monthly climatology (Schwarb et al., 2001). The resulting daily analysis (referred to as CH02D) serves the disaggregation in Section 3.3. 
Table I. Rain rates used for each reflectivity category in the radar images.

\begin{tabular}{|c|c|}
\hline $\begin{array}{l}\text { Upper bound of radar } \\
\text { reflectivity } \\
\text { categories }\end{array}$ & $\begin{array}{l}\text { Rain rates } \\
\text { used for each } \\
\text { category }\end{array}$ \\
\hline $0.0 \mathrm{~mm} / \mathrm{h}$ & $0.0 \mathrm{~mm} / \mathrm{h}$ \\
\hline$<10^{0} \mathrm{~mm} / \mathrm{h}=1.0 \mathrm{~mm} / \mathrm{h}$ & $10^{-0.25} \mathrm{~mm} / \mathrm{h}=0.6 \mathrm{~mm} / \mathrm{h}$ \\
\hline$<10^{0.5} \mathrm{~mm} / \mathrm{h}=3.1 \mathrm{~mm} / \mathrm{h}$ & $10^{0.25} \mathrm{~mm} / \mathrm{h}=1.8 \mathrm{~mm} / \mathrm{h}$ \\
\hline$<10^{1} \mathrm{~mm} / \mathrm{h}=10.0 \mathrm{~mm} / \mathrm{h}$ & $10^{0.75} \mathrm{~mm} / \mathrm{h}=5.6 \mathrm{~mm} / \mathrm{h}$ \\
\hline$<10^{1.5} \mathrm{~mm} / \mathrm{h}=31.6 \mathrm{~mm} / \mathrm{h}$ & $10^{1.25} \mathrm{~mm} / \mathrm{h}=18.8 \mathrm{~mm} / \mathrm{h}$ \\
\hline$<0^{2} \mathrm{~mm} / \mathrm{h}=100.0 \mathrm{~mm} / \mathrm{h}$ & $10^{1.75} \mathrm{~mm} / \mathrm{h}=56.2 \mathrm{~mm} / \mathrm{h}$ \\
\hline$>10^{2} \mathrm{~mm} / \mathrm{h}=100.0 \mathrm{~mm} / \mathrm{h}$ & $10^{2.25} \mathrm{~mm} / \mathrm{h}=177.8 \mathrm{~mm} / \mathrm{h}$ \\
\hline
\end{tabular}

The archived radar images hold a reflectivity category index spanning a logarithmic rain rate range. This study uses a representative rain rate for each reflectivity class.

For this study, the daily analysis of rain-gauge data is accomplished onto a regular latitude-longitude grid with a resolution of $0.020833^{\circ} \times 0.020833^{\circ}$ corresponding to approximately $2 \mathrm{~km}$, close to the $2 \mathrm{~km}$ resolution of the radar (Section 2.2). The station spacing of the raingauge network is coarser than the grid spacing and hence the effective resolution of the resulting analysis is coarser than the nominal resolution of the grid. A detailed uncertainty analysis suggests that the effective resolution of the daily analysis is in the order of 15-20 km (Frei et al., 2008).

\subsection{Pre-processing of radar data}

Originally, the radar data is available on a $2 \times 2 \mathrm{~km}$ grid every $5 \mathrm{~min}$ in the form of discrete rain rate categories. In a pre-processing step this data was transformed (regridded) onto the grid of the daily rain-gauge analysis (Section 3.1), aggregated to hourly average rain rates, and converted from a discrete into a continuous representation. For the re-gridding a simple nearest-neighbor approach was chosen. Considering that the effective resolution of the final product is coarser than the nominal resolution anyway, this seemed to be a justifiable decision.

As for the aggregation and conversion of rain rates, the twelve radar fields pertinent to the same hour have been summed up into hourly precipitation totals. For each of the categories a specific 'average' rain rate value was chosen in the summation (Table I). These values correspond to the category centres in units of radar reflectivity (Litschi, 2005). This procedure takes into account the exponential character of the rain rate frequency distribution. It reflects the fact that the values are closer to the lower rain rate bound of the corresponding category. A similar operation - i.e. transformation into precipitation rate units - was adopted to finally aggregate hourly fields to daily fields. As for the final product, the radar images merely provide the (relative) spatial structure of the precipitation (the absolute amount is taken from rain gauges), we do not consider the uncertainty within the precipitation classes as relevant.
The generation of hourly radar fields using the above scheme resulted in a high number of isolated nonzero pixels particularly in earlier periods of the dataset. These originate likely from surface clutter and other nonmeteorological backscattering (e.g. by airplanes, birds, insects). Clutter prevention and elimination procedures have been continually improved in the operational radar composite in Switzerland (Joss et al., 1998; Germann et al., 2006) but some treatment seemed to be necessary for early periods of the dataset. We have therefore filtered isolated radar echoes (defined as non-zero precipitation surrounded by zero precipitation) from the entire dataset.

\subsection{Disaggregation}

The final step in the development of the hourly dataset constitutes in a simple temporal disaggregation of the daily precipitation totals according to the evolution of rainfall seen by the radar composite. This procedure combines the advantages of the rain-gauge analysis (high absolute accuracy at the daily time scale) with that of the radar (high temporal resolution). By construction the disaggregation does not take advantage of the higher spatial resolution in the radar fields.

The disaggregated hourly rain $R$ at a position $x$ and time (h) $t_{i}$ is calculated as follows:

$$
R\left(\vec{x}, t_{i}\right)=\frac{E\left(\vec{x}, t_{i}\right)}{\sum_{t_{i}} E\left(\vec{x}, t_{i}\right)} R_{d}(\vec{x}) ; \quad 1<t_{i}<24
$$

Here, $E$ is the hourly precipitation estimate from the radar aggregates and $R_{d}$ the daily precipitation sum from the interpolated rain-gauge data (CH02D). This disaggregation distributes the daily total into hourly slices but preserves the daily precipitation totals. In the following, we will refer to the novel disaggregated precipitation dataset as $\mathrm{CH} 02 \mathrm{H}$ (in distinction to the daily dataset CH02D of Section 3.1).

The following rules have been defined to handle missing or contradicting observations. Whenever the raingauge observation is missing for a day, the disaggregation will yield missing values for all hours of that day. This occurred very rarely near the border of the country when an isolated rain gauge had no observation. Complications also arise when the aggregated daily radar total is zero, but the rain-gauge analysis indicates non-zero precipitation. In such cases it was decided to distribute the daily total uniformly, i.e. into 24 equal parts, but these occurrences were also flagged in the final dataset. In this way users depending on continuous and uninterrupted time series (e.g. for hydrological modelling) will be able to make use of the dataset, while others can omit these periods from their analysis.

Figure 2 depicts the fraction of days when a non-zero rain-gauge total was going along with a strictly zero radar total. Over most regions of Switzerland, the rate of such contradictions was in the order of $5 \%$ or lower. However a higher frequency of these cases is evident in the Eastern Alps (Grisons), where 25\% and more days 


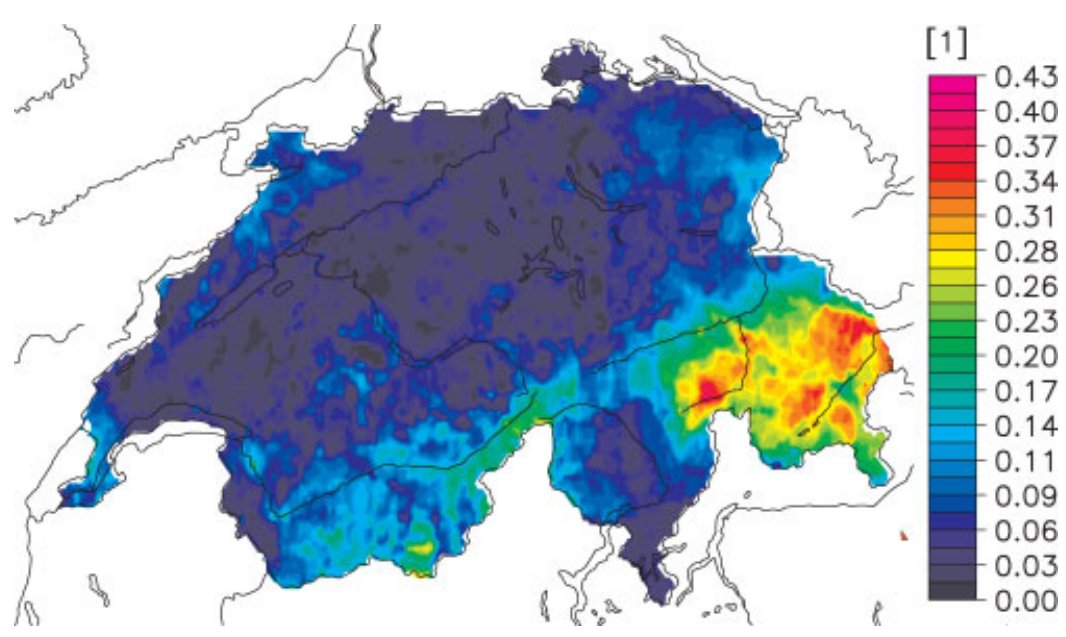

Figure 2. Fraction of days when the aggregated radar composite shows zero precipitation but the daily rain-gauge analysis (CH02D) has non-zero precipitation. For such situations the disaggregation is not unambiguous. In areas with a high frequency the hourly dataset is of minor quality. This figure is available in colour online at www.interscience.wiley.com/ijoc
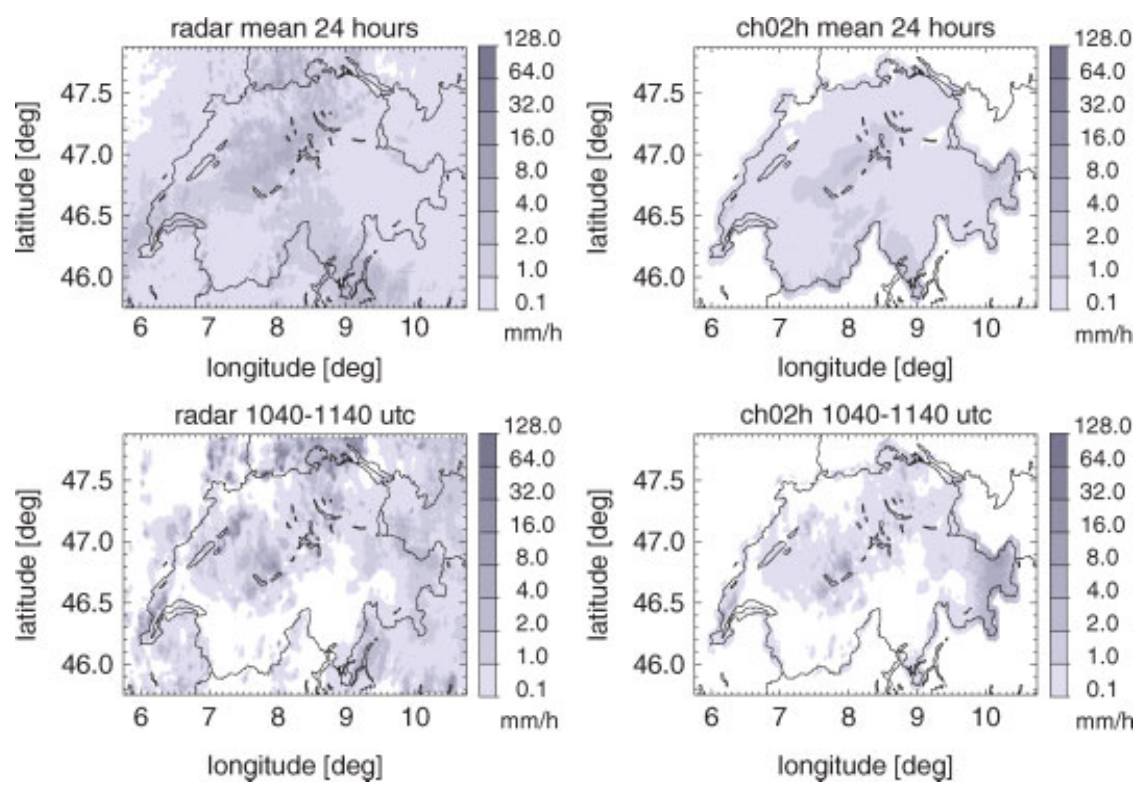

Figure 3. The 20 August 2005, as example for the disaggregation of precipitation rates. The upper panels show the average precipitation rates for this day (from 0540 UTC of 20 August 2005 to 0540 UTC of 21 August 2005) retrieved from the original radar images and from CH02D (rain-gauge analysis). The lower panels show the rain rates for one specific hour (1040-1140 UTC) of the same day. This figure is available in colour online at www.interscience.wiley.com/ijoc

are affected. This region is particularly far from the radar stations and the high elevations in this region suggest that shadowing effects (factor B in Section 2.2) might significantly deteriorate the radar signal in this region. Further evidence for this is provided in Section 4 and we anticipate that the hourly dataset is of limited quality in this region.

Figure 3 illustrates an example of the disaggregation for a flood day on 20 August 2005. The upper panels compare the daily total from the radar estimates (Table I) with the rain-gauge analysis $\mathrm{CHO2D}$ (which equals the daily total of $\mathrm{CH} 02 \mathrm{H}$ ). The radar overestimates the precipitation total for this day e.g. near the Jura Mountains in north-western Switzerland (focus on $47.0^{\circ} \mathrm{N}, 7.5^{\circ} \mathrm{E}$ ). However, this error is not transferred to the $\mathrm{CH} 02 \mathrm{H}$ product in the bottom-right panel. Although the radar total for e.g. the hour 1040-1140 UTC (bottomleft panel) contributes to the error, it is corrected in $\mathrm{CHO} 2 \mathrm{H}$, as by design the absolute disaggregated precipitation sum is based on CH02D, and not on the radar total.

\section{Dataset evaluation}

In this Section we evaluate the hourly dataset $\mathrm{CHO} H$ with respect to its representation of the rainfall evolution at local scales. For this purpose the dataset is compared to observed time series from the automatic rain-gauge network in Switzerland (Section 2.1; Figure 1b). In this comparison we proceed from a discussion of example 

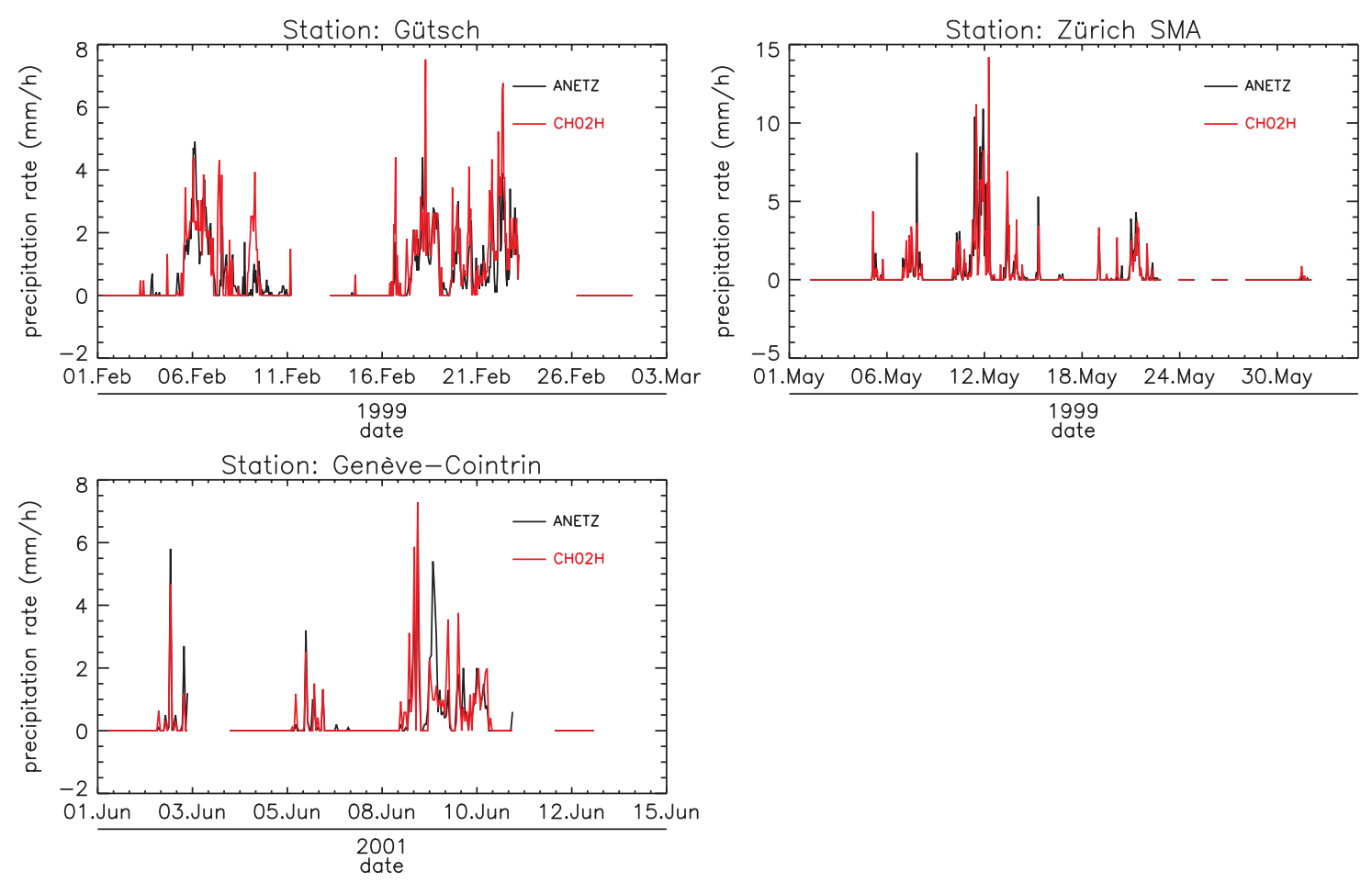

Figure 4. Time series of rain rates from three selected ANETZ rain gauges (10 min resolution) and from the nearest $\mathrm{CH} 02 \mathrm{H}$ grid point, respectively. This figure is available in colour online at www.interscience.wiley.com/ijoc

time series over aspects of the frequency distribution to systematic measures of temporal correlation.

Strictly, a time series at a grid point of the $\mathrm{CH} 02 \mathrm{H}$ dataset is not comparable to a station series because the effective resolution of the dataset is larger than $10 \mathrm{~km}$ (Section 3.1). The primary aim here is to test the reliability of the dataset with respect to variations in time, which are brought in from the radar and hence, nevertheless carry local information.

\subsection{Comparison for selected stations}

Figure 4 compares observed time series and the corresponding results in the $\mathrm{CH} 02 \mathrm{H}$ dataset (closest grid point to the automatic station). The three panels are for three different stations and they cover a time window of one calendar month each. They were chosen to illustrate typical features of the comparison.

Firstly, there is a high degree of correspondence in the temporal evolution for all three cases and the amplitude of the hourly precipitation peaks is reasonably reproduced by the $\mathrm{CHO} 2 \mathrm{H}$ dataset (red lines). However, at station Zürich and Geneva (one panel each in Figure 4) there is a tendency towards underestimation of precipitation peaks. Similar behaviour was found for many stations of the Swiss Plateau (flatland regions). It is most likely a consequence of the difference in spatial sampling between radar and point measurements (factor C, Section 2.2).

The reversed situation is observed for stations in the inner parts of the Alps (Figure 4, station Gütsch). Precipitation peaks tend to be overestimated. This behaviour is caused by the limited radar lifetime of precipitation systems in Alpine valleys (factor B, Section 2.2). Preservation of 24-hour totals will inflate the precipitation peaks if the length of the rainy period is underestimated. Such situations are more pronounced during summer in Alpine valleys.

It should be noted that the gridded $\mathrm{CH} 02 \mathrm{D}$ daily precipitation totals do not exactly match the station totals, because the rain-gauge analysis does include information from neighbouring stations even at the grid points collocated with a station. Hence, differences in the peak amplitude could also arise from differences in mean values. In the following we correct for differences in mean values by uniformly scaling the values at the $\mathrm{CHO2H}$ grid point to match the mean of the validation station.

Figure 5 compares the frequency distribution of the mean-corrected disaggregation with that from the automatic station. The diagrams depict the conditional exceedence frequency, i.e. the frequency is normalized with the duration of precipitation (computed by using a $0.1 \mathrm{~mm} / \mathrm{h}$ precipitation threshold). The results reflect the previously noted differences in the behaviour at flatland and highalpine stations. On the flatland (station Buchs-Suhr, left panel), $\mathrm{CHO} 2 \mathrm{H}$ is fairly close to the climatological frequency distribution, but there is a general underestimation particularly for high intensities and in summer. Over the high-mountain areas of the inner Alps (station GrimselHospitz, right panel) $\mathrm{CH} 02 \mathrm{H}$ overestimates exceedence frequency. Here the differences are substantial. For example, the frequency of events exceeding $10 \mathrm{~mm} / \mathrm{h}$ is overestimated in $\mathrm{CH} 02 \mathrm{H}$ by more than a factor of 10 . Note that these large overestimates are qualitatively and partly 

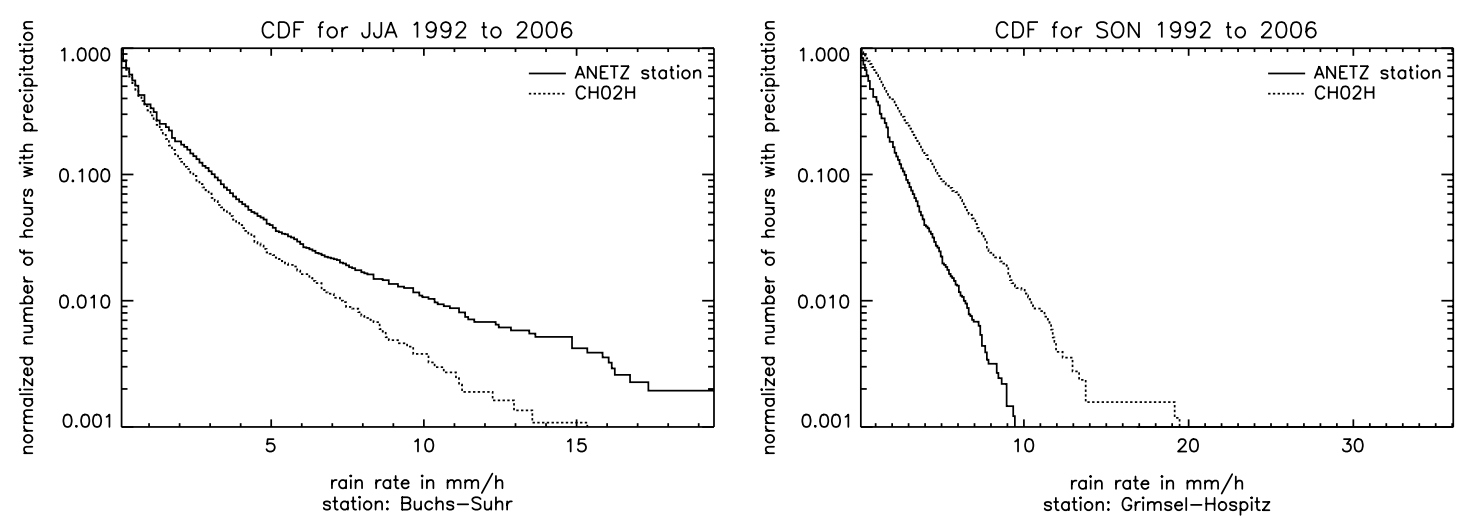

Figure 5. Conditional cumulative distribution function (CDF, exceedence frequency) of hourly precipitation totals compared between stations (full lines) and $\mathrm{CH} 02 \mathrm{H}$ (dotted). Left panel: Buchs-Suhr (Swiss Plateau, summer months). Right panel: Grimsel-Hospitz (high-Alpine station, autumn months). The $\mathrm{CH} 02 \mathrm{H}$ values are corrected for the difference in the mean precipitation between $\mathrm{CH} 02 \mathrm{H}$ and ANETZ.

compensated by too few precipitation hours in $\mathrm{CH} 02 \mathrm{H}$, due to the limited visibility by the radar.

\subsection{Precipitation frequency and intensity}

Here we examine the performance of the $\mathrm{CH} 02 \mathrm{H}$ dataset in a systematic comparison at the location of all 72 recording rain-gauges ANETZ in Switzerland (Figure 1b). Two parameters will be considered: firstly the ratio of wet-hour frequencies,

$$
\frac{F_{\mathrm{D}}}{F_{\mathrm{S}}}
$$

$F_{\mathrm{D}}$ is the frequency of precipitation hours (i.e. an hourly total equal to or larger than $0.1 \mathrm{~mm}$ ) in the disaggregation $(\mathrm{CH} 02 \mathrm{H})$ and $F_{\mathrm{S}}$ the corresponding frequency at the validation station. The second parameter is an intensity ratio corrected for differences in the mean. It is defined as:

$$
\frac{I_{\mathrm{D}} / I_{\mathrm{S}}}{M_{\mathrm{D}} / M_{\mathrm{S}}}
$$

Here $M_{\mathrm{D}}$ and $M_{\mathrm{S}}$ represent mean precipitation of $\mathrm{CH} 02 \mathrm{H}$ and the co-located station respectively. $I_{\mathrm{D}}$ and $I_{\mathrm{S}}$ are precipitation intensities, i.e. the average precipitation rate during wet hours (using the same threshold of $0.1 \mathrm{~mm}$ ). The scaling of the intensity ratio with the ratio of mean values is a way to correct for differences in the mean value. Obviously, a good climatological performance of $\mathrm{CHO} 2 \mathrm{H}$ will reflect in values of the frequency and intensity ratios close to one. In all these evaluations we have focussed on those periods of the dataset when precipitation could be regularly disaggregated, i.e. radar echoes were present when there was a non-zero daily total in CH02D (Section 3.3).

Figure 6 depicts the results from the evaluation separately for winter and summer. In the area of the Swiss Plateau, the Jura and the Ticino, the precipitation frequency and intensity are within about $25 \%$ of the observed point values. In these regions there is a tendency to overestimate precipitation frequencies (more squares than diamonds), particularly in summer but to a lesser extent also in winter. Not surprisingly, these biases go along with a tendency to underestimate hourly precipitation intensities as the daily totals are distributed over too long rain periods on average. One possible factor for this is the larger spatial sampling of a radar measurement compared to that of a rain-gauge (factor $\mathrm{C}$ in Section 2.2), which tends to temporally extend rainfall events. This factor may be particularly effective in convective periods in summer when rain phases are short and numerous. Nevertheless this effect is quantitatively moderate and we conclude that $\mathrm{CH} 02 \mathrm{H}$ reasonably represents climatological characteristics of the local precipitation frequency distribution.

In contrast, much larger biases are found in inner Alpine areas. There are pronounced frequency underestimates and intensity overestimates at many stations in the Grisons and the Valais. In this case the largest biases are found in the winter season, but a similar pattern is evident in summer. In these mountainous regions the limited radar visibility (i.e. shadowing of mountain valleys, factor B in Section 2.2) obviously results in too short precipitation phases and in turn into exaggerated intensities by the disaggregation. Apparently this is more effective in winter, when precipitation systems are more shallow compared to convection in summer. Note that these biases can be quite substantial, reaching frequency underestimates (intensity overestimates) by a factor of two and more.

It can be summarized that $\mathrm{CHO} 2 \mathrm{H}$ can exhibit large deviations in mean frequency and intensity in the highmountain regions far from the radar locations (particularly the Valais and Grisons). Over the Swiss Plateau and Ticino the results are fairly good. Here, the mean frequency and intensity in the disaggregated dataset are within plus/minus $25 \%$ of the locally observed values for all seasons.

\subsection{Temporal evolution}

In this subsection we systematically quantify the temporal coherence, i.e. the alignment of precipitation peaks, between $\mathrm{CHO} 2 \mathrm{H}$ and the co-located recording gauge. As 

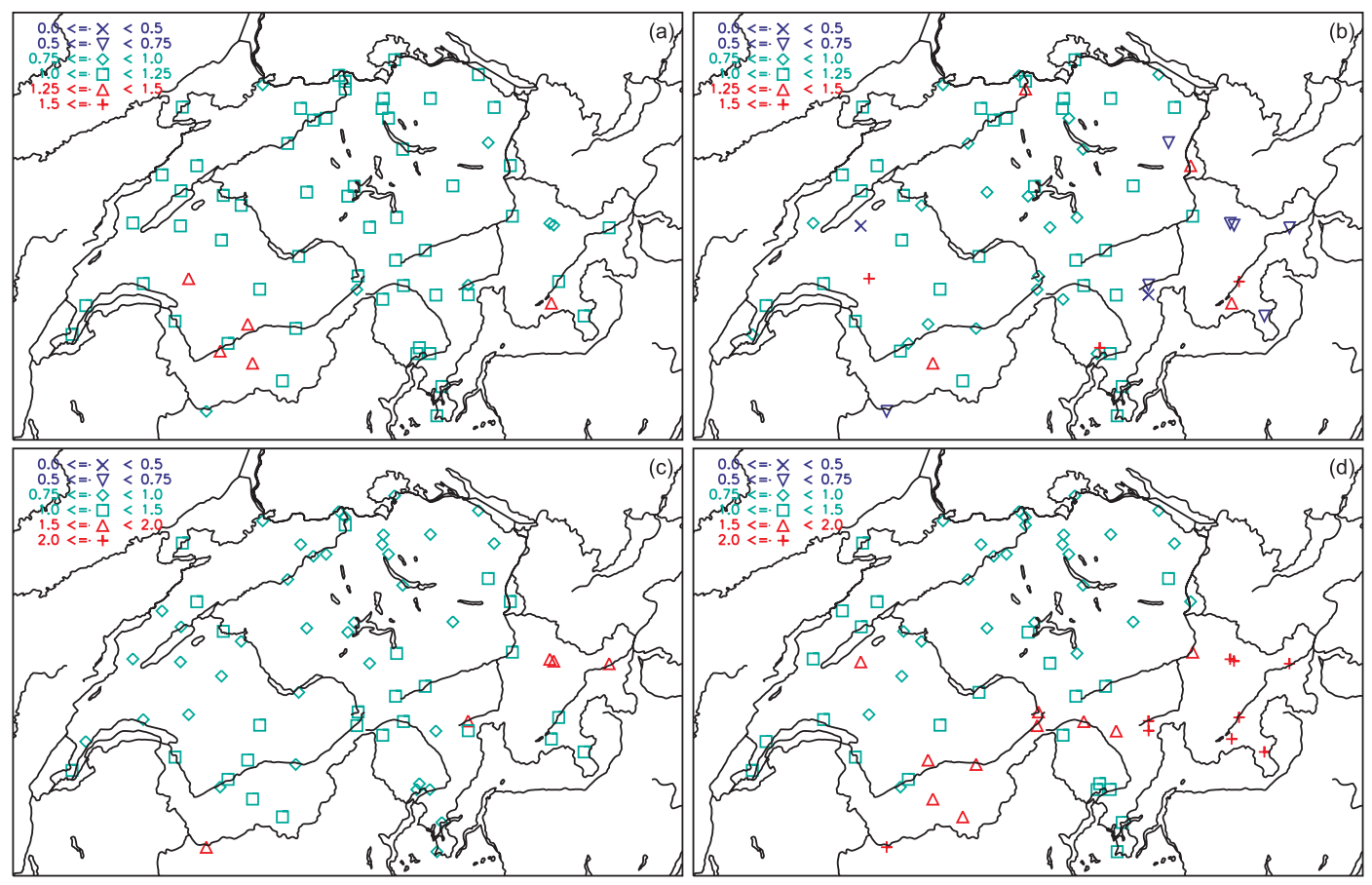

Figure 6. Frequency $(\mathrm{a}, \mathrm{b})$ and intensity ratios $(\mathrm{c}, \mathrm{d})$ between $\mathrm{CH} 02 \mathrm{H}$ and recording gauges in Switzerland. For the definition of these parameters refer to Equations. (2) and (3). Results are shown for summer (left) and winter (right). Note the key for symbol types and colors in the legends. This figure is available in colour online at www.interscience.wiley.com/ijoc

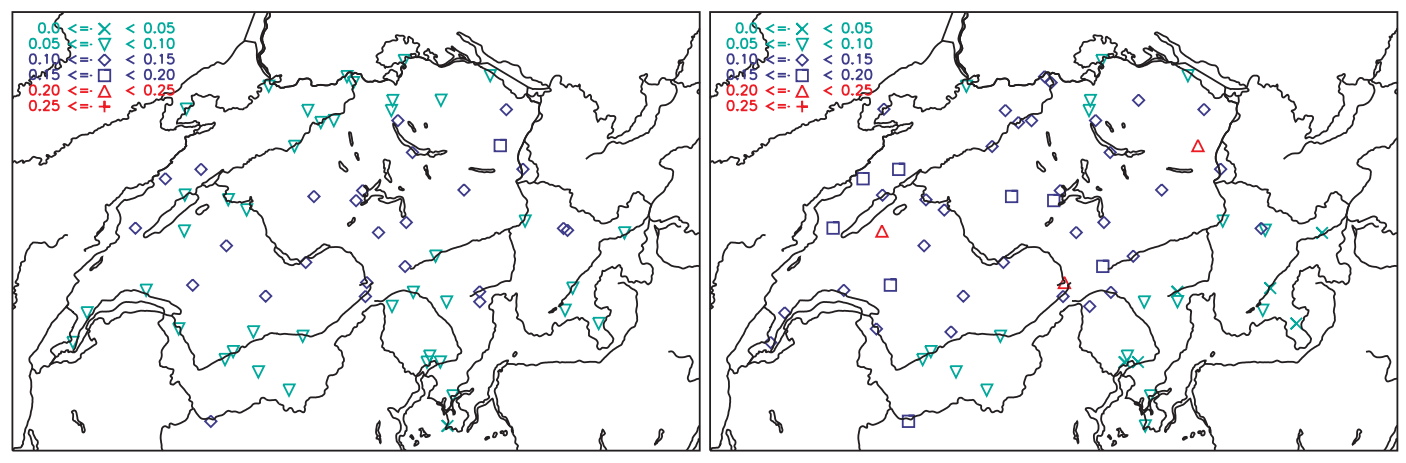

Figure 7. Mean absolute difference (MAD, Equation (4) ) between $\mathrm{CH} 02 \mathrm{H}$ and locally observed hourly precipitation series for summer (a) and winter (b). This figure is available in colour online at www.interscience.wiley.com/ijoc

quality measure we choose a standardized version of the mean absolute difference (MAD). It is defined as

$$
\mathrm{MAD}=\frac{1}{n} \sum_{i=1}^{n}\left|\frac{r_{\mathrm{D}_{i}}}{I_{\mathrm{D}}}-\frac{r_{\mathrm{S}_{i}}}{I_{\mathrm{S}}}\right|
$$

Here $r_{\mathrm{D} i}$ and $r_{\mathrm{S} i}$ represent hourly time series (with $n$ samples) of the disaggregation and the station respectively. The scaling of hourly precipitation rates by the respective climatological precipitation intensity should (1) make this score less sensitive to systematic biases (quantified in the previous subsection already) and (2) make MAD comparable between stations with different mean intensities. Note that in comparison to the more common root mean square error measure, MAD is less sensitive to extreme values.

Figure 7 depicts MAD values evaluated over the entire analysis periods 1992-2003 separately for summer and winter. Firstly, there are comparatively little systematic differences between the seasons. (This is also confirmed in similar analyses for spring and autumn.) Secondly, MAD values are generally smaller than 0.2 , indicating that $\mathrm{CH} 02 \mathrm{H}$ is typically within $20 \%$ of the local station value (after correcting for systematic errors). Two of the stations showing larger discrepancies are high-mountain top stations (Säntis in eastern Switzerland, Pilatus in central Switzerland). Here some part of the discrepancy may also be due to errors and/or poor representativeness of the gauge measurements themselves. There is comparatively little spatial variation in the MAD values. They are slightly smaller in the flatlands of the Swiss Plateau and southern Ticino as compared to the northern slopes of the Alpine Mountain Range.

In summary, the major discrepancies between $\mathrm{CH} 02 \mathrm{H}$ and recording gauges seem to be primarily of a systematic nature and from the perspective of random errors there 

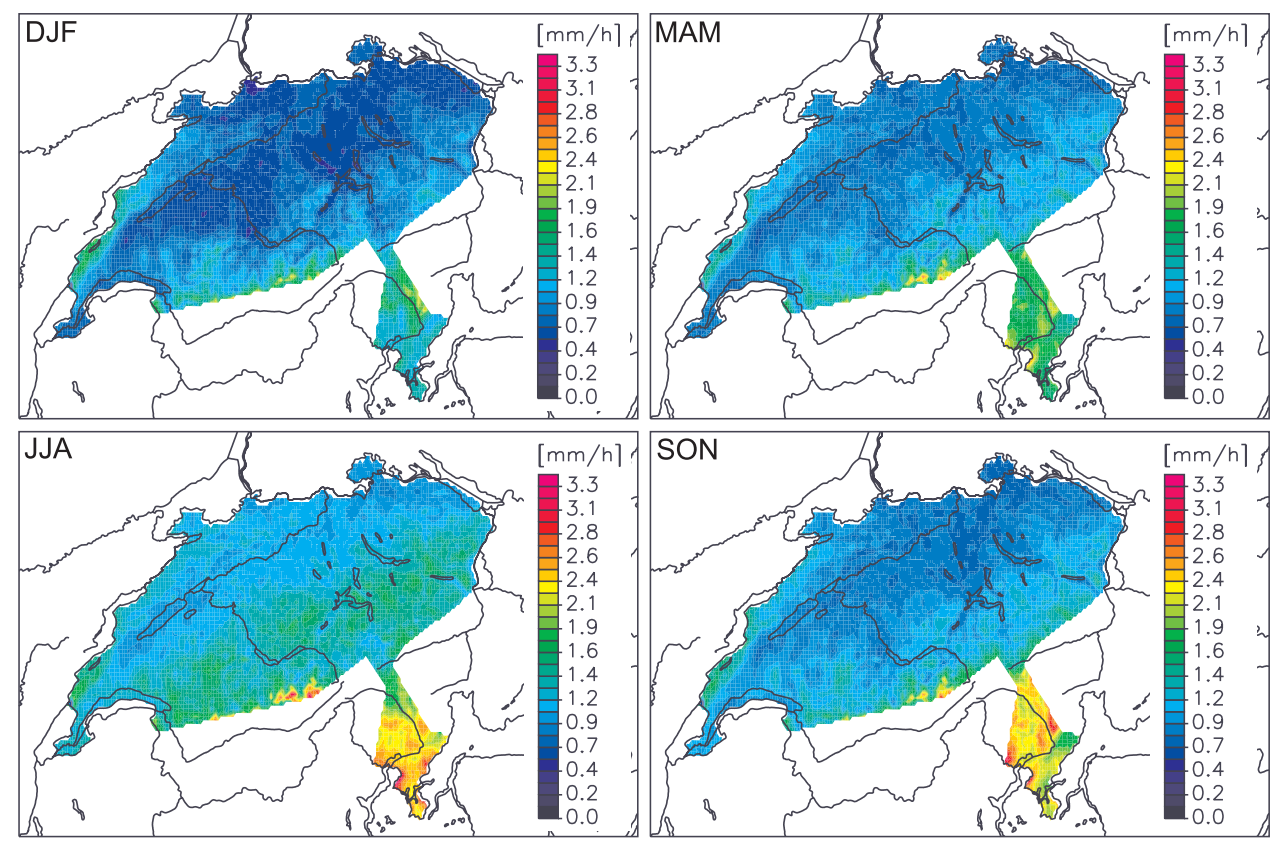

Figure 8. Mean hourly precipitation intensity, defined as the average precipitation during wet hours (precipitation $>0.1 \mathrm{~mm} / \mathrm{h}$ ). The panels are for the four seasons and the analysis period is 1992-2006. This figure is available in colour online at www.interscience.wiley.com/ijoc

is no need to further constrain the area where $\mathrm{CH} 02 \mathrm{H}$ can be taken as a reliable dataset of hourly precipitation evolution.

\section{Illustration and climatology}

The new dataset constitutes a gridded, hourly analysis, which extends over a climatological period of now more than 15 years in Switzerland. In this section we present results for 1992-2006. The dataset enables climatological studies of precipitation variability at much shorter time scales than that was possible from conventional daily analyses. Considering the important role of short-term precipitation peaks, for example, for the runoff in small river catchments and for urban hydrology, the dataset offers interesting applications and insights for regional hydrology. In this section we illustrate a few examples from a climatological analysis of the new dataset for Switzerland.

The evaluation in Section 4.2 has identified problems of the disaggregation technique related to the limited radar visibility in high-mountain areas and inner Alpine valleys. In a given situation, the magnitude of these errors depends on the meteorological characteristics of the precipitation event and hence the need for taking account of the errors will depend on the application of the dataset. For the applications in this section we have restrictively masked out all areas with a potential intensity and frequency bias (Section 4), that is, all high-mountain areas in the interior of the Alps, notably the regions Valais and Grisons (Figure 1).

\subsection{Intensity distribution}

The first example investigates elements of the intensity distribution. Figure 8 depicts the average hourly precipitation intensity, defined as the mean precipitation during wet hours, i.e. with a minimum amount of $0.1 \mathrm{~mm}$. Results are shown for the four seasons. Obviously to the north of the Alps the largest intensity is found in summer when convective storms are frequent. But there is considerable regional variation: In the region of the northern foothills the intensity is almost twice that over the Swiss Plateau. Except for its westernmost parts, the Jura Mountains do not receive significantly larger intensities compared to the flatland as one would have anticipated from the frequent triggering of thunderstorms over this hill range. The largest hourly precipitation intensities are found in southern Switzerland. In this region the intensity is larger in autumn compared to summer. Even though typical precipitation events in this season are more longlasting, related to continued southerly flow and associated orographic lifting (Schär et al., 1998; Martius et al., 2006) the mean hourly precipitation intensity seems to exceed that from summer-time convection.

Additional features of the high-frequency precipitation climatology are depicted in Figure 9 which juxtaposes the frequency of wet hours (precipitation $>0.1 \mathrm{~mm} / \mathrm{h}$ ) to the frequency of heavy precipitation (precipitation $>10 \mathrm{~mm} / \mathrm{h}$ ). To the north of the Alpine main crest, the mean frequency of wet hours is comparatively smooth both in winter and summer. Contrasts seem to be more pronounced in summer than in winter, which is plausible from the more local convective nature of precipitation formation in summer. Somewhat enhanced frequencies are found over areas closer to the northern Alps, a likely effect of the convective triggering in these regions in summer and of the orographic lifting during westerly and north-westerly flow situations in winter. To the south of the main crest, wet-hour frequency is found to be comparable to that of the Swiss flatlands in summer 

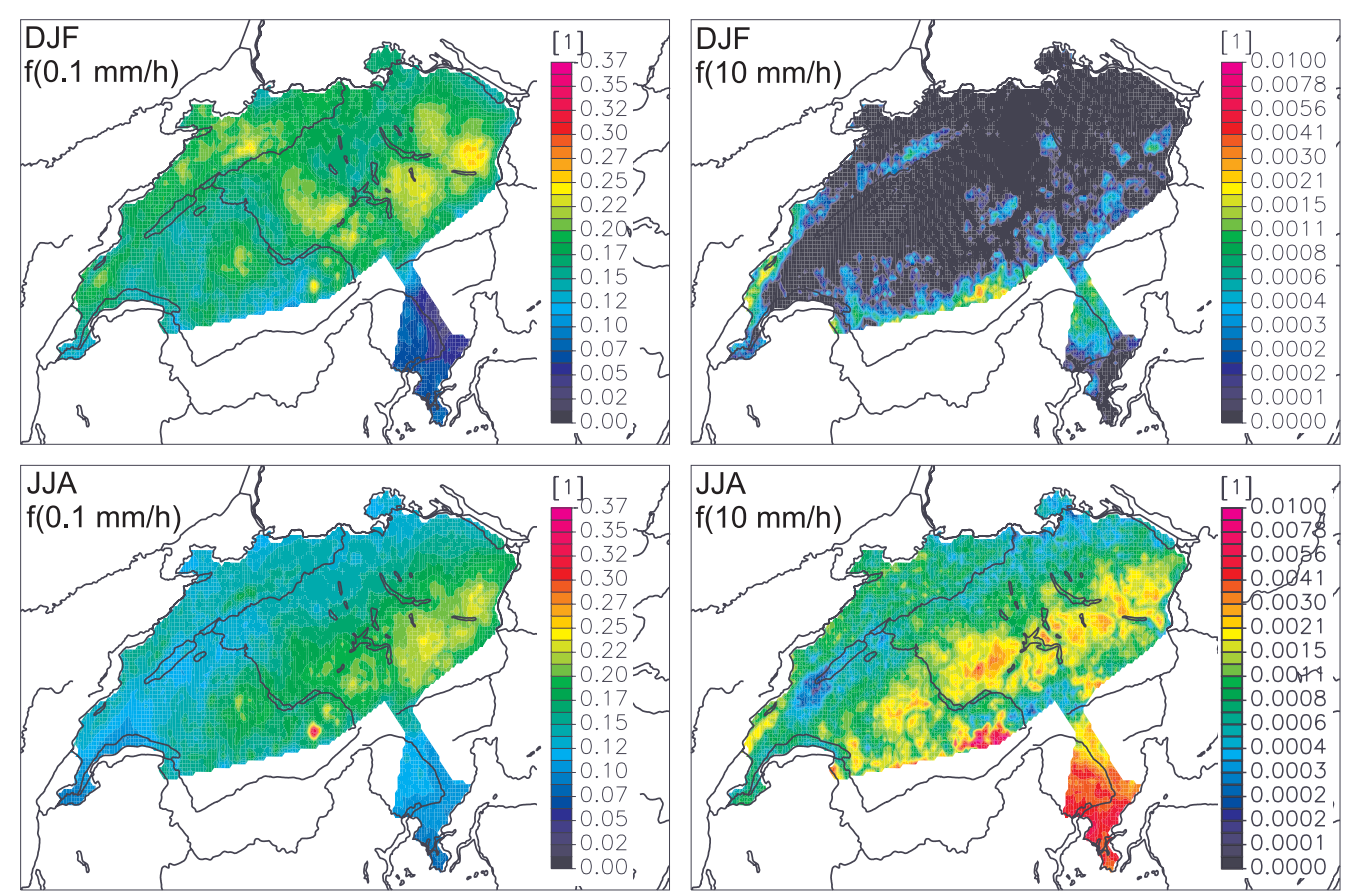

Figure 9. Mean frequencies of wet hours (precipitation $>0.1 \mathrm{~mm} / \mathrm{h}$, left) and heavy precipitation (precipitation $>10 \mathrm{~mm} / \mathrm{h}$, right) for winter (top row) and summer (bottom row). This figure is available in colour online at www.interscience.wiley.com/ijoc
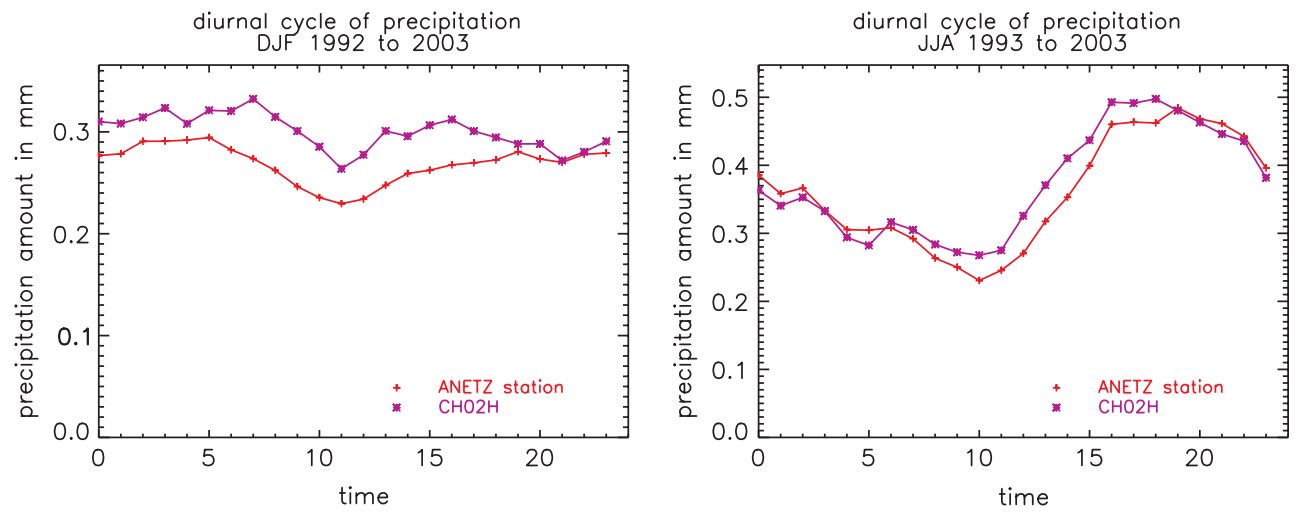

Figure 10. Diurnal cycle of hourly precipitation in winter (a) and summer (b). Results are displayed for the average of automatic rain gauge stations (crosses) and for the average of all grid pixels of $\mathrm{CH} 02 \mathrm{H}$ at the rain gauge stations. In both cases only stations/pixels located in the unmasked domain of $\mathrm{CH} 02 \mathrm{H}$ were selected (Figure 8) based on data from 1992-2006. This figure is available in colour online at www.interscience.wiley.com/ijoc

but less than half of it in winter. On the other hand, the frequency of heavy hourly precipitation shows much more regional and seasonal variations than the wet-hour frequency. In summer heavy precipitation is substantially stronger in southern Switzerland, compared to the north. Moreover in winter, heavy precipitation hours virtually don't occur in northern Switzerland.

\subsection{Diurnal cycle}

Figure 10 depicts the mean diurnal cycle of hourly precipitation in Switzerland. The analysis compares results from the $\mathrm{CH} 02 \mathrm{H}$ dataset with those from recording rain gauges. Only pixels co-located with the automatic rain gauges have been used in the analysis (for direct comparability) but averaging over all $\mathrm{CH} 02 \mathrm{H}$ pixels yields very similar patterns.
In summer there is well pronounced diurnal cycle with a minimum before noon and a maximum in late afternoon. The cycle differs clearly from a strict sinusoidal signal. The average rain rate increases rapidly during the afternoon, remains high till about 20 UTC, and then gradually decreases during the night and the morning. In winter there is only a slight indication of a diurnal cycle, yet the small signal shows a similar overall pattern with a minimum before noon and an extended maximum from evening till early morning.

The diurnal cycle for the $\mathrm{CH} 02 \mathrm{H}$ dataset is very similar to that inferred from the recording gauges both with respect to amplitude and phase of the signal. There is a slight discrepancy in that, the increase continues further into the late evening in the stations' records. Considering that considerable random errors must be 
expected in the diurnal cycle as a result of the high precipitation variability in summer (many zeros $v s$ high intensities), the correspondence between the two datasets is very satisfactory. This is an additional corroboration of the disaggregation technique, because the temporal evolution in $\mathrm{CHO} 2 \mathrm{H}$ is entirely determined from the radar sequences.

\section{Conclusions}

$\mathrm{CH} 02 \mathrm{H}$ is a new hourly precipitation dataset combined from weather radar and rain-gauge observations. It steps into the sub-daily resolution by disaggregating a daily gridded rain-gauge analysis with the help of hourly radar sequences. The rain-gauge analysis makes full use of all available gauges including the dense network of conventional, not automated, daily measurements. The disaggregation retains the daily precipitation sums of the rain-gauge analysis and hence reduces effects from quantitative radar errors. At the same time robustness is assured in the spatial distribution by the absence of extrapolations. The implementation and data availability allow a precipitation rate analysis over a climatological time scale even today.

The method was applied for a 15 -year period and validated in this article focussing the quality and representativeness of the disaggregated rain rates. The application of the method for Switzerland, i.e. the product $\mathrm{CH} 02 \mathrm{H}$ promises reliable and accurate hourly precipitation rates for the Swiss Plateau and the Ticino. The validation indicates errors in hourly intensity and frequency of less than $25 \%$ in average. The Alpine valleys (Valley, Grisons) show greater errors in the hourly rate due to shielding effects of the radar. In these valleys errors could only be reduced in the future with additional radar coverage.

$\mathrm{CH} 02 \mathrm{H}$ offers to be a representative and robust precipitation rate analysis for Switzerland. It has already been used for orographic precipitation studies and the validation of numerical weather prediction and climate models (e.g. Hohenegger et al., 2008a, 2008b; Hoose et al., 2008). The hourly resolution and decadal scale coverage appear also well suited for the frequency analysis of extreme precipitation and for the forcing of hydrological models.

The presented method could equivalently be applied to and validated in other regions. It ideally requires homogeneous coverage by rain-gauge and radar networks. Most of the European rain-gauge networks appear of sufficient coverage and homogeneity, while the availability and quality of radar data is rather diverse.

The $\mathrm{CHO} 2 \mathrm{H}$ product will continuously be extended into the future using the operational rain-gauge and radar observations. We are also discussing a retrieval of the eighties' data to expand the climatology to the past. As the computing time is small (less than an hour per year of data on a typical workstation) we can consider to investigate different versions of the climatology with tailored filtering of missing data. We are looking forward to get into contact with interested groups. Information on the status and distribution of the $\mathrm{CHO} 2 \mathrm{H}$ product can be found at www.iac.ethz.ch/url/ch02h.

\section{Acknowledgements}

We are grateful to the Federal Office of Meteorology and Climatology MeteoSwiss for the provision of the raingauge and radar observations used in this study.

\section{References}

Auer I, Böhm R, Jurkovic A and coauthors. 2005. A new instrumental dataset for the greater Alpine region for the period 1800-2002. International Journal of Climatology 25: 139-166.

Barbosa S. 1994. Brief review of radar-raingauge adjustment techniques. In Advances in radar hydrology, Almeida-Teixeira ME, Fantechi R, Moore R, Silva VM (eds). European Commission: Brussels 148-169, EUR 14334 EN.

Borga M, Tonelli F, Moore RJ, Andrieu H. 2002. Long-term assessment of bias adjustment in radar rainfall estimation. Water Resources Research 38: 1-10, 1226. DOI:10.1029/2001WR000555.

Daly C, Neilson RP, Philipps DL. 1994. A statistical-topographic model for mapping climatological precipitation over mountainous terrain. Journal of Applied Meteorology 33: 140-158.

Frei C, Germann U, Fukutome S, Liniger M. 2008. Möglichkeiten und Grenzen der Niederschlagsanalysen zum Hochwasser 2005. In Ereignisanalyse Hochwasser 2005: Teil 2 -Analyse von Prozessen, Massnahmen und Gefahrengrundlagen, Bezzola GR, Hegg C (eds). Bundesamt für Umwelt, Eidgenössische Forschungsanstalt WSL. Umwelt-Wissen Nr0825: Bern, Switzerland; 15-32.

Frei C, Schär C. 1998. A precipitation climatology of the Alps from high-resolution rain-gauge observations. International Journal of Climatology 18: 873-900.

Frei C, Schöll R, Fukutome S, Schmidli J, Vidale PL. 2006. Future change of precipitation extremes in Europe: Intercomparison of scenarios from regional climate models. Journal of Geophysical Research 111: DOI:10.1029/2005JD005965.

Guo J, Liang X, Leung LR. 2004. Impact of different precipitation data sources on water budgets. Journal of Hydrology 298: 311-334.

Haberlandt U. 2007. Geostatistical interpolation of hourly precipitation from rain-gauge and radar for a large-scale extreme rainfall event. Journal of Hydrology 332: 144-157.

Hagen M. 1999. The Alpine Radar Composite. MAP-Newsletter 11: 20-21.

Hohenegger C, Brockhaus P, Schär C. 2008a. Towards climate simulations at cloud-resolving scales. Meteorologische Zeitschrift 17(4): 383-394.

Hohenegger C, Walser A, Langhans W, Schär C. 2008b. Cloud resolving ensemble simulations of the August 2005 Alpine flood. Quarterly Journal Royal Meteorological Society 134(633): 889-904.

Hoose C, Lohmann U, Stier P, Verheggen B, Weingartner E. 2008. Aerosol processing in mixed-phase clouds in ECHAM5-HAM: model description and comparison to observations. Journal of Geophysical Research 113: D07210. DOI:10.1029/2007JD009251.

Joss J, Schädler B, Galli G, Cavalli R, Boscacci M, Held E, Bruna G, Kappenberger G, Nespor V, Spiess. 1998. Operational Use of Tadar for Precipitation measurements in Switzerland. Vdf Hochschulverlag AG ETH Zurich: 134.

Joss J, Waldvogel A. 1990. Precipitation measurements and hydrology. In Radar in Meteorology, Atlas D (ed). American Meteorological Society: Boston, MA, USA; 577-606.

Klok EJ, Klein Tank AMG. 2009. Updated and extended European dataset of daily climate observations. International Journal of Climatology 29: 1182-1191.

Koistinen J, Michelson DB. 2002. BALTEX weather radar-based precipitation products and their accuracies. Boreal Environment Research 7: 253-263.

Konzelmann T, Wehren B, Weingartner R. 2007. Niederschlagsmessnetze. Hydrological Atlas of Switzerland, HADES: 20. Available from University of Bern, Plate 2.1: Bern, Switzerland.

Martius O, Zenklusen E, Schwierz C, Davies H. 2006. Episodes of Alpine heavy precipitation with an overlying elongated stratospheric intrusion: A climatology. International Journal of Climatology 26: 1149-1164. 
Meischner P, Collier C, Illingworth A, Joss J, Randeu W. 1997. Advanced Weather Radar Systems in Europe: the COST 75 Action. Bulletin of the American Meteorological Society 78: 1411-1430.

Neary VS, Habib E, Fleming M. 2004. Hydrologic modelling with NEXRAD precipitation in Middle Tennessee. Journal of Hydrologic Engineering 339: 339-350. DOI: 10.1061/ASCE 1084-0699 2004 9: 5

Neff EL. 1977. How much rain does a rain gage gage? Journal of Hydrology 35: 213-220.

New M, Hulme M, Jones P. 1999. Representing twentieth-century space-time climate variability. Part I: development of a 1961-1990 mean monthly terrestrial climatology. Journal of Climate 12: 829-856.

Schär C, Davies TD,Frei C, Wanner H, Widmann M, Wild M, Davies HC. 1998. Current alpine climate., Chapter 2. In Views from the Alps: Regional perspectives on climate change, Cebon P, Dahinden U, Davies HC, Imboden DM, Jäger C (eds). MIT press: Boston, $21-72$.

Schmidli J, Frei C. 2005. Trends of heavy precipitation and wet and dry spells in Switzerland during the 20th century. International Journal of Climatology 25: 753-771.
Schwarb M, Daly C, Frei C, Schär C. 2001. Mean annual precipitation throughout the European Alps, 1971-1990. Hydrological Atlas of Switzerland, Plates 2.6 and 2.7. University of Berne: Switzerland. http://hydrant.unibe.ch/hades.

Seo D-J. 1998. Real-time estimates of rainfall fields using radar rainfall and rain gauge data. Journal of Hydrology 208: 37-52.

Shepard D. 1968. A two-dimensional interpolation function for irregularly-spaced data. Proceedings of the 1968 23rd ACM National Conference, Princeton, NJ, USA; 517-524.

Shepard D. 1984. Computer mapping: The SYMAP interpolation algorithm. In Spatial Statistics and Models. D. Reidl Publishing Company: Dordrecht, 133-145.

Widmann M, Bretherton CS. 2000. Validation of mesoscale precipitation in the NCEP reanalysis using a new gridcell dataset for the northwestern United States. Journal of Climate 13(11): 1936-1950. Yang DQ, Elomaa E, Tuominen A, Aaltonen A, Goodison B, Gunther T, Golubev V, Sevruk B, Madsen H, Milkovic J. 1999. Windinduced precipitation undercatch of the Hellmann gauges. Nordic Hydrology 30: 57-80. 